\title{
Dysembryoplastic neuroepithelial tumour: A case report
}

\author{
Khaled A ${ }^{1}$, Joarder A ${ }^{2}$, Chandy $\mathrm{M}^{3}$, Nasir TA ${ }^{4}$
}

\begin{abstract}
Aim and Objective: Dysembryoplastic neuroepithelial tumour is an unusual brain tumour with varied incidence commonly occurring in younger age groups. We report a 16 year old female diagnosed as a case of dysembryoplastic neuroepithelial tumour.

Clinical presentation: a 16 year old female was examined for headache and convulsion for two months. MRI revealed a brain tumor which was later confirmed as dysembyroplastic neuroepithelial tumor by histopathological examination.
\end{abstract}

Conclusion: DNET is a relatively rare brain tumor and needs differentiation from other closely resembling brain tumor because of its favorable prognosis.

Key Words: brain tumor, Dysembryoplastic neuroepithelial tumor, epilepsy.

Introduction: Dysembryoplastic neuroepithelial tumor was first proposed by Daumas-Duport in 1988. ${ }^{1}$ DNT is characterized as mixed neuronal-glial tumor in the current WHO classification of CNS tumors corresponding to WHO grade. $^{\text {I2 }}$ This tumor demonstrates typical histological features such as glial nodules and the so-called glioneuronal element. ${ }^{3,4}$ DNTs are clinically associated with drug-resistant focal or secondary generalized seizures arising in childhood probably due to an up-regulation of several multi-drug transporters. ${ }^{5,6}$ The vast majority of these tumors have been reported in the cortex with the temporal lobe being most common. In up to one third of cases contrast enhancement in MRI is observed. ${ }^{7}$ Their favorable prognosis is also due to the fact that most lesions remain stable, yet rare cases with slow progression or hemorrhage due to hamartomatous vessels have been reported. ${ }^{8,9}$ Outcome after surgical resection has also been considered favorable, as the majority of children remain seizure-free. ${ }^{10}$ In contrast, a long history of epilepsy, older age at time of surgery and adult cases are associated with poor seizure control. ${ }^{11}$ Rarely, cases with multi-focal lesions $^{12-16}$ or familial occurrence ${ }^{1,17}$ have been described. There are very few reports of DNTs with elevated proliferative activity that underwent transformation into malignant gliomas at a later stage. ${ }^{18,19}$

As the lesion carries a favorable prognosis and these patients do not require radiation following surgery, it becomes very essential that this lesion should be accurately diagnosed by the surgical pathologist. Besides, there is no published report of DNET from our country so far. With this background knowledge, in this case report we describe the clinical and histo-morphological features in a patient with DNET.

Case History: A 16 year old non diabetic, normotensive female came in the neurosurgery out patient department of Apollo hospital Dhaka with the complaint of left sided headache for two months associated with decreased hearing for one month and history of convulsion 1.5 month back. She also gave history of convulsion for few times two years back. A family history of CNS malformation or neurofibromatosis was excluded. Additionally no family member had a positive history for intracranial tumor. Her Glasgow coma scale score was 15(E4V5M6). Her routine neurological examination and laboratory examination were within normal limit. MRI revealed a well defined lesion in the left temporal fossa posteriorly abutting the cranial vault and tentorium cerebelli. Brilliant enhancement noted on contrast study. After taking written informed consent, left occipito-temporal craniotomy and excision of the mass was done and specimen sent for histopathological examination. Grossly the specimen was one lobulated grayish-white piece of tissue measuring $3.5 \times 2.5 \times 3 \mathrm{~cm}$ having macrogyri like appearance. On sectioning it shows homogenosity with viscous consistency. On microscopic examination, it shows glial nodules in association with specific glioneuronal elements and foci of cortical dysplasia. The heterogenous appearance is due to proliferation of pleomorphic cells composed of astrocytes, oligodendrocytes and neuronal elements. Areas of focal myxoid change, microcystic changes and vascular proliferation are also noted (Fig: 1).

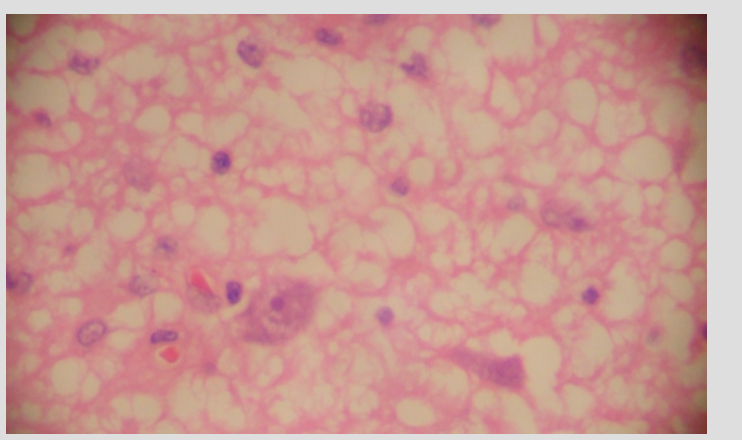

Figure 1: Oligodendroglial like cells and floating neurons within myxoid background in dysembryoplastic neuroepithelial tumour.

A diagnosis histomorphologically consistent with Dysembryoplastic neuroepithelial tumour was made. 


\section{Dysembryoplastic neuroepithelial}

\begin{abstract}
Discusssion: The morphologic features of DNT consisting of a preferential cortical topology, multinodular architecture and the young age of onset, led to the hypothesis that DNT is an own tumor entity and may be derived from the secondary germinal layers. ${ }^{1}$ Histopathological hallmarks are bundles of axons lined by oligodendroglia-like cells, forming columns in a pale mucoid matrix in which isolated neurons float. These so-called glioneuronal elements are observed both in simple and complex forms of DNT. The heterogenous appearance of the latter is due to additional glial or neuronal cell populations which mimic low-grade gliomas. Our patient presented with a clinical history of focal epileptic seizures and histology showed the typical features of DNT including glioneuronal elements. Additionally, the tumor contained mainly oligodendroglial components and few astrocytic and neuronal areas in disarranged cortical layers. Thus, the diagnosis of a DNT, complex variant, WHO grade I was made.
\end{abstract}

A non-specific variant of DNT without typical glioneuronal elements has been proposed by Daumas-Duport. ${ }^{3}$ These are histologically indistinguishable from certain low-grade gliomas. One case without typical glioneuronal elements but mature ganglion cells within a multinodular architecture has been reported in the literature. ${ }^{20}$ Because of this histopathological confusion with oligodendroglioma, low grade glioma and ganglion cell tumor, neuroradiological appearance together with clinical presentation always needs to be taken into consideration. ${ }^{21}$

Most DNTs show no or a very low proliferative activity, with MIB-1 labeling indices usually being $<1 \%$. However, few cases with occasional mitotic activity and elevated MIB-1 index $(28 \%)$ which is more typical for high-grade gliomas, have been reported. ${ }^{1,4,18,19}$ In addition, despite a traditionally benign course, in rare cases of elevated proliferative activity DNT might undergo transformation to malignant gliomas. ${ }^{18,19}$ Although no exact numbers are known, extracortical located DNTs are rare. Onguru and colleagues reported a case in the floor of the anterior horn of the left lateral ventricle. ${ }^{22}$ Five cases of DNT in the caudate nucleus, partially extending into the ventricles and one in the septum of the lateral ventricles have been described so far. ${ }^{23,24}$ Infratentorial located DNTs are even rarer and have been reported in the tectum, cerebellum, ${ }^{12,15}$ pons ${ }^{15}$ and brainstem. ${ }^{12}$ Multifocal DNTs were observed in cases with neurofibromatosis type ${ }^{1,14}$ XYY syndrome $^{13}$ and surrounding cortical dysplasia, 15,16

Since most patients with DNET following surgery have shown excellent recovery and the seizure in them are more or less fully controlled. These patients need not to be subjected to any radiation or chemotherapy. Therefore it is essential that DNET should be accurately diagnosed. ${ }^{21}$ However the concept of DNET is evolving further as new investigations are carried out. ${ }^{2}$
References:

1. Daumas-Duport C, Scheithauer BW, Chodkiewicz JP, Laws ER Jr, Vedrenne C. Dysembryoplastic neuroepithelial tumor: a surgically curable tumor of young patients with intractable partial seizures. Report of thirty-nine cases. Neurosurgery. 1988;23:545-556.

2. Daumas-Duport C, Pietsch T, Lantos P. In: Kleihues P, Cavenee WK, editors. Dysembryoplasticneuroepithelial tumour. Pathology and Genetics of Tumours of the Nervous System. Lyon: IARC Press; 2000.p. 103-106.

3. Daumas-Duport C, Varlet P, Bacha S, Beuvon F, Cervera-Pierot P, Chodkiewicz JP. Dysembryoplastic neuroepithelial tumors: nonspecific histological forms- a study of 40 cases. J Neurooncol. 1999:41:267-280

4. Prayson RA, Morris HH, Estes ML, Comair YG. Dysembryoplastic neuroepithelial tumor: a Clinicopathologic and immunohistochemical study of 11 tumors including MIB1 immunoreactivity. Clin Neuropathol. 1996;15:47-53

5. Vogelgesang S, Kunert-Keil C, Cascorbi I. Expression of multidrug transporters in Dysembryoplastic neuroepithelial tumors causing intractable epilepsy. Clin Neuropathol. 2004; 23:223-231.

6. Wolf HK, Zentner J, Hufnagel A Surgical pathology of chronic epileptic seizure disorders: experience with 63 specimens from extratemporal corticectomies, lobectomies and functional hemispherectomies. Acta Neuropathol. 1993; 86: 466-472.

7. Shin JH, Lee HK, Khang SK. Neuronal tumors of the central nervous system: radiologic findings and pathologic correlation. Radiographics. 2002;22:1177-1189.

8. Ostertun B,Wolf HK, Campos MG. Dysembryoplastic neuroepithelial tumors:MR and CT evaluation. Am J Neuroradiol. 1996; 17:419-430.

9. Thom M, Gomez-Anson B, Revesz T. Spontaneous intralesional haemorrhage in Dysembryoplastic neuroepithelial tumours: a series of five cases. J Neurol Neurosurg Psychiatry. 1999; 67:97-101.

10. Nolan MA, Sakuta R, Chuang N. Dysembryoplastic neuroepithelial tumors in childhood: long-term outcome and prognostic features. Neurology. 2004;62:2270-2276.

11. Aronica E, Leenstra S, van Veelen CW. Glioneuronal tumors and medically intractable epilepsy: a clinical study with long-term followup of seizure outcome after surgery. Epilepsy Res. 2001;43:179-191.

12. Fujimoto K, Ohnishi H, Tsujimoto M, Hoshida T, Nakazato Y Dysembryoplastic neuroepithelial tumor of the cerebellum and brainstem. Case report. J Neurosurg. 2000;93:487-489.

13. Krossnes BK, Wester K, Moen G, Mork SJ. Multifocal dysembryoplastic neuroepithelial tumor in a male with the XYY syndrome. Neuropathol Appl Neurobiol. 2005;31:556-560.

4. Lellouch-Tubiana A, Bourgeois M, Vekemans M, Robain O. Dysembryoplastic neuroepithelial tumors in two children with neurofibromatosis type 1. Acta Neuropathol. 1995:90:319-322.

15. Leung SY, Gwi E, Ng HK, Fung CF, Yam KY. Dysembryoplastic neuroepithelial tumor: a tumor with small neuronal cells resembling oligodendroglioma. Am J Surg Pathol. 1994;18:604-614.

16. Whittle IR, Dow GR, Lammie GA, Wardlaw J. Dsyembryoplastic neuroepithelial tumor with discrete bilateral multifocality: further evidence for a germinal origin. Br J Neurosurg. 1999:13:508-511.

17. Hasselblatt M, Kurlemann G, Rickert CH. Familial occurrence of dysembryoplastic neuroepithelial tumor. Neurology. 2004;62:10201021.

18. Hammond RR, Duggal N, Woulfe JM, Girvin JP. Malignant transformation of a dysembryoplastic neuroepithelial tumor. Case report. J Neurosurg. 2000;92:722-725.

19. Rushing EJ, Thompson LD, Mena H. Malignant transformation of a dysembryoplastic neuroepithelial tumor after radiation and chemotherapy. Ann Diagn Pathol. 2003;7:240-244.

20. Iwanaga K, Takahashi H, Kameyama S, Tanaka R, Ikuta F Dysembryoplastic neuroepithelial tumor: report of a case without typical glioneuronal elements. Acta Neuropathol.1995;89:284-289.

21. Burger PC, Scheithauer BW, editors. Tumors of the central nervous system. Atlas of Tumor Pathology. 3rd series. Washington, DC: Armed Forces Institute of Pathology; 1994. p. 184-187.

22. Onguru O, Deveci S, Sirin S, Timurkaynak E, Gunhan O. Dysembryoplastic neuroepithelial tumor in the left lateral ventricle. Minim Invasive Neurosurg. 2003;46:306-309. p184-187

23. Guesmi H, Houtteville JP, Courtheoux P, Derlon JM, Chapon F. Dysembryoplastic neuroepithelial tumors: report of 8 cases including two with unusual localization. Neurochirurgie. 1999;45:190-200.

24. Cervera-Pierot P, Varlet P, Chodkiewicz JP, Daumas-Duport C. Dysembryoplastic neuroepithelial tumors located in the caudate nucleus area: report of four cases. Neurosurgery. 1997;40:1065-1069.

25. Kurtkaya-Yapicier O, Elmaci I, Boran B, Kilic T, Sav A, Pamir MN. Dysembryoplastic neuroepithelial tumor of the midbrain tectum: a case report. Brain Tumor Pathol. 2002;19:97-100. 